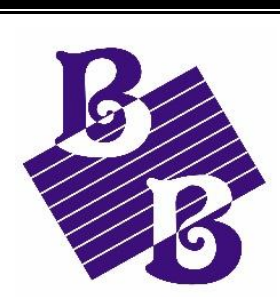

BioBacta

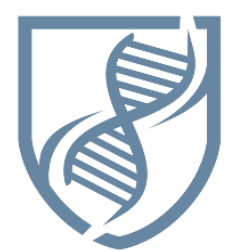

Journal of Bioscience and Applied Research www.jbaar.org



\title{
Curcumin suppresses cellular adhesion and migration of A549 lung cancer cells via a LIMK1/MLCK dependent mechanism
}

\author{
Ahmed A. Soffar ${ }^{1}$, Cecil A. Matta $^{2}$, Saleh O. Albatati ${ }^{3}$ \\ 1. Division of Molecular Biology, Department of Zoology, Faculty of Science, Alexandria University, Alexandria, \\ Egypt. \\ 2. Department of Zoology, Faculty of Science, Alexandria University, Alexandria, Egypt. \\ 3. Basic Medical Sciences Department, College of Medicine, Mukalla-B.O: (50512-50511), Hadhramaut, Yemen. \\ Corresponding Author: Dr. Ahmed A. Soffar E-mail address: ahmedsoffar@gmail.com; ahmed.soffar@alexu.edu.eg \\ DOI: $10.21608 /$ jbaar.2019.147118
}

\begin{abstract}
:
Cancer cell migration is a major cause of mortality in lung cancer patients. Despite intensive research regarding its efficacy in cancer treatment, the anti-metastatic properties of curcumin have been poorly investigated. Therefore, this work aims to explore the potential anti-migratory and anti-adhesive properties of curcumin on lung cancer cells. We also investigated the underlying molecular mode of action of curcumin. We performed scratch and adhesion assays to investigate the migratory and adhesive potentials of A549 cells. The cellular topological differences upon curcumin treatment were investigated using Scanning Electron Microscope. We also investigated the molecular mechanism triggered by curcumin using quantitative realtime PCR. Also, we performed an MTT toxicity assay to explore the toxic potential of curcumin on cancer cells. The student's $t$-test was applied for evaluating the data significance using Microsoft Excel 2016. Our results showed that curcumin attenuates the migration and adhesion of A549 cancer cells at non-toxic concentrations. By coincidence, the scanning electron microscope study showed a decreased density of lamellipodia and filopodia upon curcumin treatment. Interestingly, we found that the expression levels of LIMK1 and MLCK genes were downregulated upon curcumin application. Taken together, curcumin inhibits the migration and adhesion abilities of lung cancer cells and could be used as a therapeutic agent against cancer cell migration. The underlying mechanism involves modulation of the expression levels of critical molecular targets including LIMK1 and MLCK proteins.
\end{abstract}

\section{Key-words:}

Cellular migration, Cell adhesion, Lung cancer, Curcumin, LIMK1, MLCK 


\section{Introduction:}

Lung cancer is considered the leading cause of cancer-related deaths worldwide. It contributes to more than $18 \%$ of the total cancer deaths (Bray et al. 2018). It has been estimated that $85 \%$ of lung cancer cases are non-small-cell lung carcinoma (NSCLC) and most of these patients already have metastases to other parts of their body (Popper 2016). Critically, only $4 \%$ of patients with a metastatic stage of the disease survive more than five years (Goldstraw et al. 2016).

Despite gaining major mechanistic knowledge into the metastatic process of cells, there has been limited progress in developing anti-metastatic therapeutic strategies that effectively cease the migratory behavior of cancer cells (Guo et al. 2017). Also, eradicating remote or escaping cancer cells usually acquire chemotherapeutic treatment which renders high morbidity and mortality rates as current chemotherapeutic agents fail to selectively and effectively eliminate cancer cells without destroying normal cells at the sites of metastasis $(\mathrm{Li}$ et al. 2017). Therefore, seeking novel therapeutic agents that target the migration potential of cancer cells might help to gain better clinical outcomes in lung cancer therapy.

Recently, curcumin showed several anti-tumour activities via its effect on a variety of biological pathways involved in tumorigenesis, mutagenesis, oncogene expression, apoptosis, and cell cycle regulation (Ye et al. 2012). Extensive studies revealed that the anticancer mode of action of curcumin involves critical molecular targets involved in regulating cellular adhesion, migration, and organization of the cytoskeleton (Deng et al. 2016). The critical down-stream regulators for these cellular functions are: 1) Serine/threonine LIM domain kinase 1 (LIMK1) which phosphorylates and deactivates its downstream actin filament severing protein Cofilin 1 and renders it unable to severe and depolymerize the actin filaments (Pollard 2016). 2) Non-muscle myosin light chain kinase (MLCK) which regulates cell contractility via phosphorylating the regulatory light chain of myosin 2 thus restoring the cellular motor activity (Chen et al. 2014a).

Despite intensive research regarding its antitumor efficacy, the potential anti-metastatic properties of curcumin have been poorly investigated. Therefore, this work aims to explore the potential anti-migratory and anti-adhesive properties of curcumin on lung cancer cells. Also, we will investigate the effect of curcumin on different signaling pathways that regulate cellular motility. Specifically, we will focus on the downstream proteins including Cofilin1, LIMK1, and MLCK proteins.

\section{Material and Methods:}

\section{Curcumin preparation}

Curcumin (Purity 96\%) was purchased from (Sigma, Germany). A stock solution $(100 \mathrm{mM})$ was prepared by dissolving $368.4 \mathrm{mg}$ of curcumin in $10 \mathrm{ml}$ DMSO. Further dilutions were prepared whenever necessary.

\section{Preparation of Cell Cultures}

A549 cell line was purchased from the Medical Research Institute (MRI), Alexandria University, Alexandria, Egypt. Cells were cultured in a complete medium of high glucose Dulbecco's Modified Eagle's Medium (DMEM) (with L-Glutamine) (Lonza, Belgium) containing 10\% foetal bovine serum (FBS) (Sigma, Germany) in $10 \mathrm{~cm}$ cell culture dishes. Cells were incubated in a humidified $\mathrm{CO}_{2}$ incubator (Shel Lab, USA) at $37^{\circ} \mathrm{C}$ with $5 \% \mathrm{CO}_{2}$. In all experiments, cultures of $70-80 \%$ confluence were used with a maximum passage number of 20 .

\section{Cell Migration Assay}

Cells were seeded in 24-well plates in a complete medium $\left(1.2 \times 10^{5}\right.$ cell/well). After $24 \mathrm{~h}$, confluent monolayers were scraped with a sterile $200 \mu$ tip and were rinsed twice with $1 \mathrm{ml}$ of PBS to remove cell debris. Fresh serum-free DMEM containing DMSO or curcumin $(5,10,20 \mu \mathrm{M})$ was added to each well. Images of the wound areas were taken at $0 \mathrm{~h}, 24 \mathrm{~h}$, and 
48h after treatment using an inverted phase-contrast microscope (OPTIKA, Italy) connected to a digital camera. Image analysis was performed using Image $\mathbf{J}$ software (v1.50).

\section{Cell Adhesion Assay}

Cells were seeded and treated with curcumin (10, $20 \mu \mathrm{M})$ or DMSO for $24 \mathrm{~h}$. Treated cultures were trypsinized and re-seeded in 6-well plates $\left(2 \times 10^{5}\right.$ cell/well). After $4 \mathrm{~h}$, the prepared cultures were washed with PBS and stained with $0.5 \%$ Crystal Violet solution containing $10 \%$ Glutaraldehyde for 1h. Images were taken for each well in five different areas and analyzed using the ImageJ software (v1.5). The number of adherent cells from 5 different shots/well was counted and the average number of adherent cells $/ \mathrm{mm}^{2}$ was calculated.

\section{Scanning Electron Microscopy (SEM)}

Monolayer cultures were prepared over coverslips in 24-well plates. After 24h, confluent cultures were scratched using a sterile $200 \mu$ lip, washed with PBS and treated with Curcumin or DMSO in a serum-free medium. After $48 \mathrm{~h}$, cultures were fixed using ${ }_{4} \mathrm{~F}_{1} \mathrm{G}$ fixative at $4^{\circ} \mathrm{C}$, gold-coated using ion sputtering device (JEOL, Japan) and examined and imaged using a scanning electron microscope (JEOL, Japan).

\section{Quantitative Real-Time PCR}

Gene expression level was detected using quantitative RT-PCR as previously described in (Bacevic et al. 2017) with some modifications. Total cellular RNA was extracted using RNA Extraction Kit (Thermo Fisher Scientific, Inc., USA), according to the manufacturer's protocol. Complementary DNA synthesized using cDNA Kit (Thermo Fisher Scientific, Inc.), was used for PCR. The RT-PCR reaction was performed using the TOPreal ${ }^{\mathrm{TM}} \mathrm{qPCR}$ 2X PreMIX (Enzynomics, Korea). The following primer sequences were used: Cofilin1, forward, 5'AACGACATGAAGGTGCGTAA-3', and reverse, 5'-CTCACTCAGGCAGAAGAGCA-3'; LIMK1, forward, 5'-AGACCTCAACTCCCACAA-3' and reverse 5'-CTCAGGTGCCATCCAGT-3'; MLCK, forward, 5'-GTCTTATGTTATCTTCCATTCTA-3' and

reverse

$5^{\prime}-$
TATAATAAACTGTGGCAATACTG-3';

and Ready-to-use GAPDH primers (Qiagen, Netherlands). RT-qPCR was performed in duplicate and relative expression levels of Cofilin1, LIMK1, and MLCK were normalized to GAPDH expression levels.

\section{MTT Viability Assay}

Cells were cultured with a density of $10^{4}$ cell/well in 96-well plates. After $24 \mathrm{~h}$, the culture medium was aspirated and replaced with a fresh complete medium containing Curcumin $(2.5,5,10,20 \mu \mathrm{M})$ or DMSO. At $24 \mathrm{~h}$ and $48 \mathrm{~h}$, wells were washed with PBS and supplied with $2.5 \mathrm{mg} / \mathrm{ml}$ of 3-(4,5-dimethylthiazol-2yl)-2,5-diphenyltetrazolium bromide (MTT) (SERVA, Germany) in serum-free DMEM. After $2 \mathrm{~h}$ of incubation, the wells were carefully washed with PBS and supplemented with $100 \mu \mathrm{l}$ DMSO for $15 \mathrm{~min}$ to dissolve the MTT formazan. Absorbance was read at $490 \mathrm{~nm}$ in a microplate reader (Lakshmanan et al. 2016).

\section{Statistical Analysis}

Data were expressed as mean \pm standard deviation (SD) of three independent repeats. The student's $t$ test was applied for evaluating the data significance using Microsoft Excel 2016. Results were considered statistically significant when the $p$-value $<0.05$.

\section{Results:}

\section{Curcumin attenuates cellular migration of A549 cancer cells}

First, we raised the question of whether curcumin application affects the migratory potential of cancer cells or not. Therefore, we applied the wound assay on confluent A549 monolayer cultures upon treatment with curcumin $(5,10,20 \mu \mathrm{M})$. DMSOtreated preparations were used as controls. The wound area was measured at $0,24,48 \mathrm{~h}$ after treatment (Fig.1a, b). The migratory ability of cells was expressed as \% migration about the control (Fig.1c). Our results showed that curcumin application inhibits the migration ability of cells at a concentration of $10 \mu \mathrm{M}$ and $20 \mu \mathrm{M}$ either $24 \mathrm{~h}$ or $48 \mathrm{~h}$ after treatment. The observed anti-migratory effect of curcumin was statistically significant $(p<0.05)$ at a 
high concentration of curcumin $(20 \mu \mathrm{M})$ with a $(5 \mu \mathrm{M})$ results in a slight, but not significant, increase decrease in overall migration potential of cells by about $20 \%$ as compared to controls. On the other in the migration potential of cells as compared to hand, applying a low concentration of curcumin controls.

a

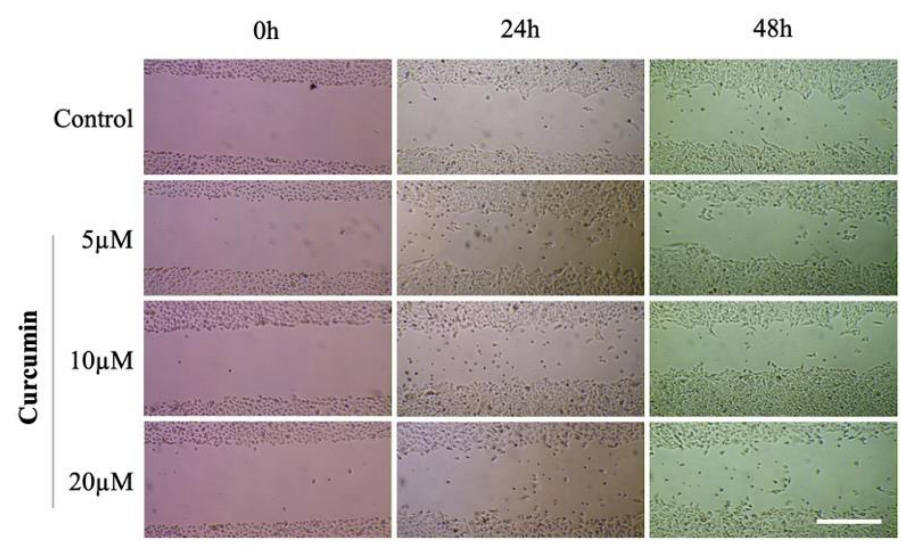

b

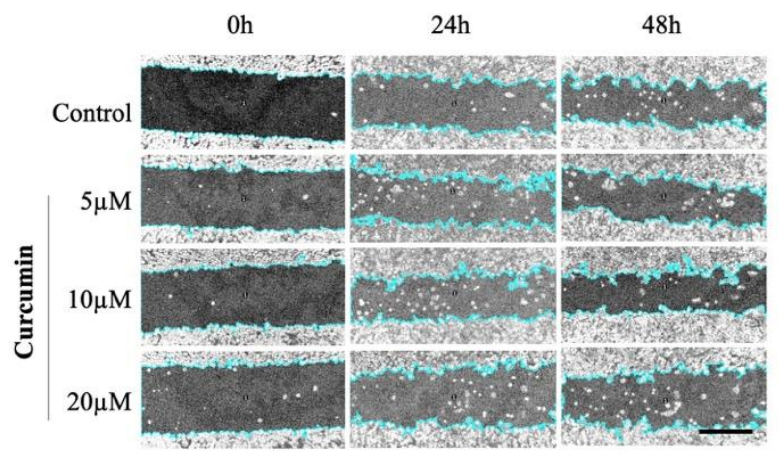

c

24h

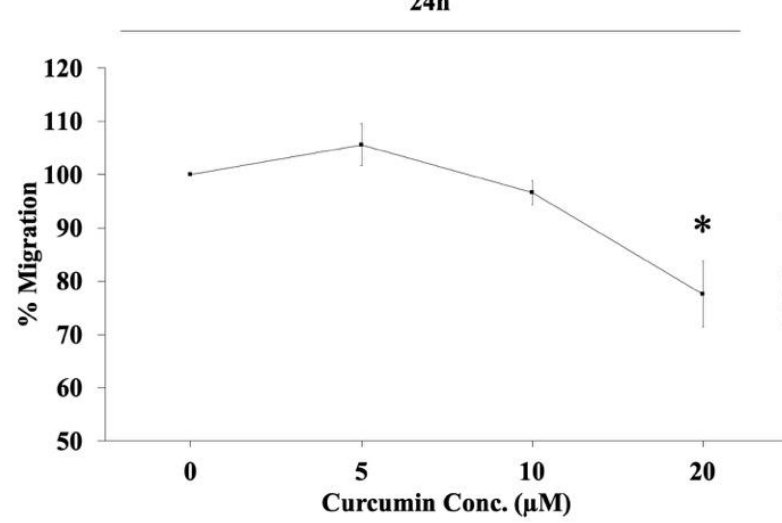

$48 \mathrm{~h}$

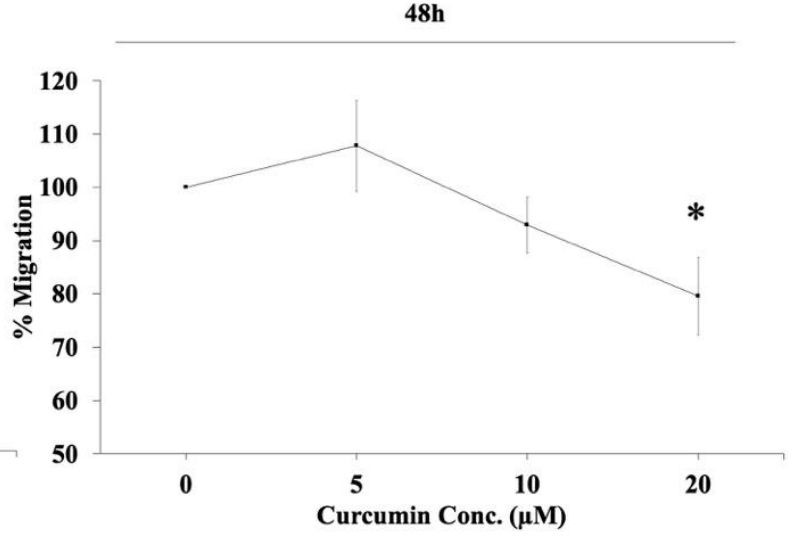

Fig.1: Curcumin attenuates A549 cancer cell migration. a. Representative phase-contrast images of the wound area of control and curcumin-treated cultures at 0,24 , or $48 \mathrm{~h}$ points after treatment. b. ImageJprocessed images showing the residual wound area (Blue line-enclosed area) upon curcumin treatment at different time points. c. Dose-response curves showing the percent fold change in wound closure area of curcumin-treated or control cultures at $24 \mathrm{~h}$ (upper curve) and $48 \mathrm{~h}$ (lower curve). Results are mean \pm s.d. ( $\mathrm{n}=$ 3 , Student's $t$-test, $* p<0.05)$. Bar, $500 \mu \mathrm{m}$. 
Curcumin alters the adhesive ability of A549 cells

We investigated the possible role of curcumin on the adhesion of cancer cells as shown in figure 2 . We observed that curcumin application decreases the number of adherent cells in a dose-dependent manner. The $\%$ of adherent cells upon curcumin application was significantly $(p<0.05)$ lowered by $21 \%$ as compared to control.

\section{a}

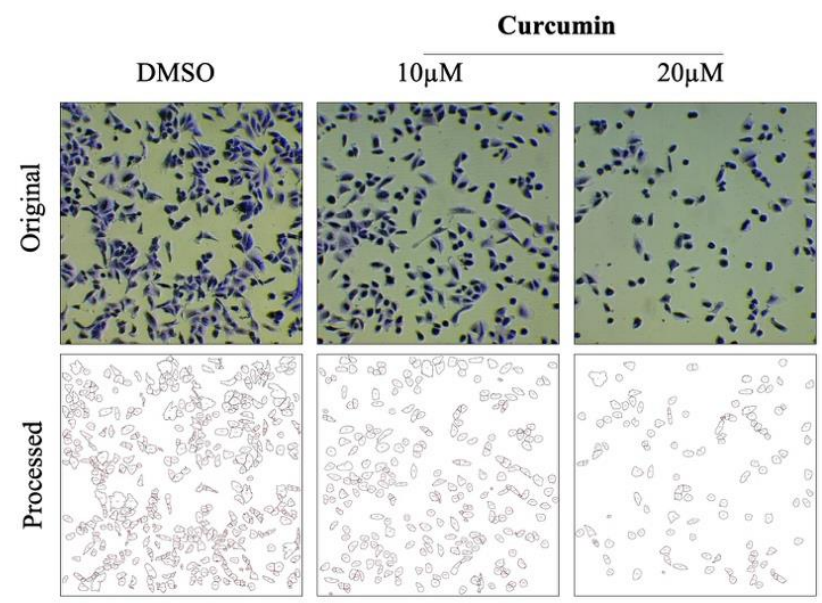

b

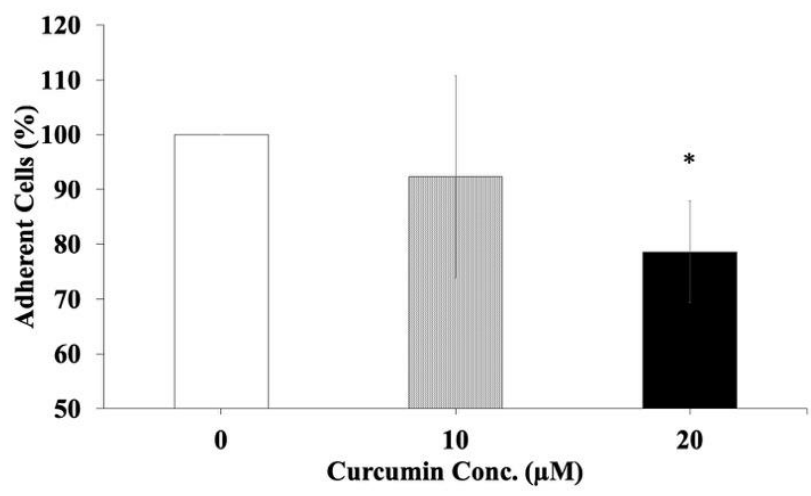

Fig. 2: Impact of Curcumin on the adhesion of A549 cancer cells. a. Representative photographs adhesion assay of A549 cultures. Images were processed using ImageJ software and the total number of adherent cells $/ \mathrm{mm}^{2}$ were counted. b. Bar graph showing the $\%$ of adherent cells in response to curcumin treatment. Results are mean \pm s.d. $\left(\mathrm{n}=3\right.$, Student's $t$-test, $\left.{ }^{*} p<0.05\right)$.

\section{Curcumin attenuates the formation of lamellipodia and filopodia}

We further investigated the morphology and surface features of cancer cells using SEM. Regarding the control samples, we found that cancer cells migrate collectively, i.e. a leading cell guides several neighboring cells to move and close the wound (Fig.3a, b). This involves a dynamic remodeling of cellular junctions and the formation of lamellipodia and filopodia. The cells appeared with long spindleshaped lamellipodia that are, in some cells, have been extended along the wound to form bridges (Fig.3b, c). At higher magnification, the control cells possess numerous filopodia extending from the lamellipodia toward the wound area (Fig.3d). In curcumin-treated cultures, we observed several topological differences when compared to the control cultures. The wound is wider with few short cellular protrusions (Fig.4a, b). Also, cells exhibited fewer lamellipodia and lacked their polarity against the wound when compared to control. Moreover, we did not observe any filopodia protruding from the curcumin-treated cells (Fig.4c, d). 
a

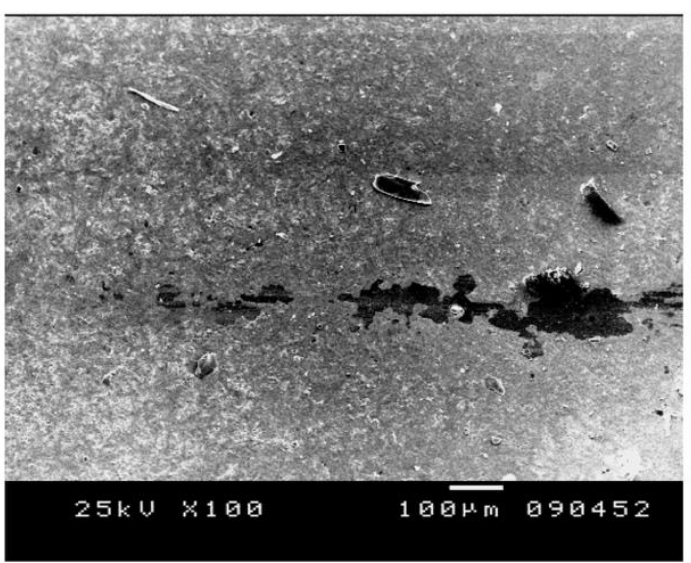

c

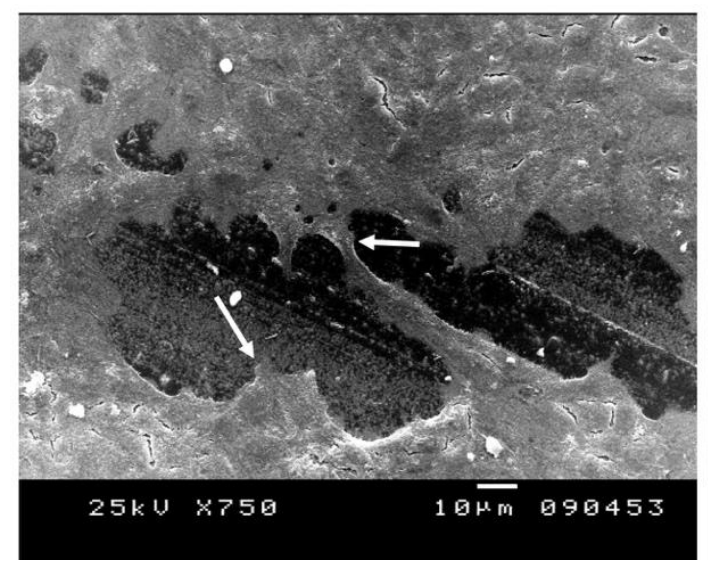

b

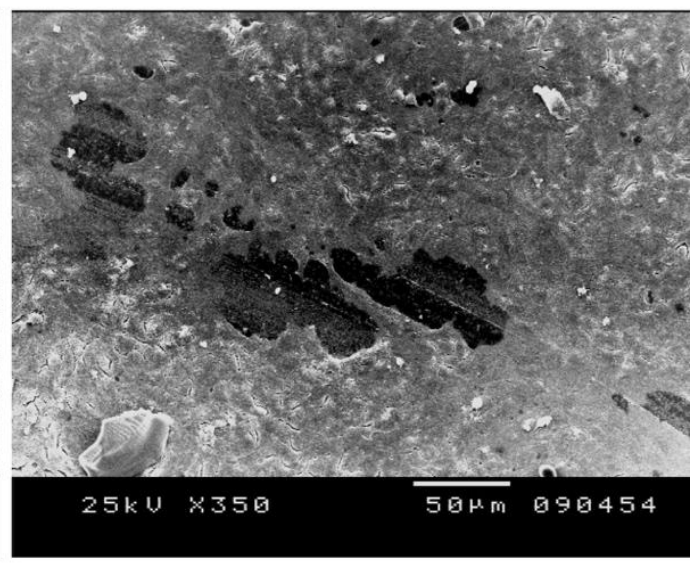

d

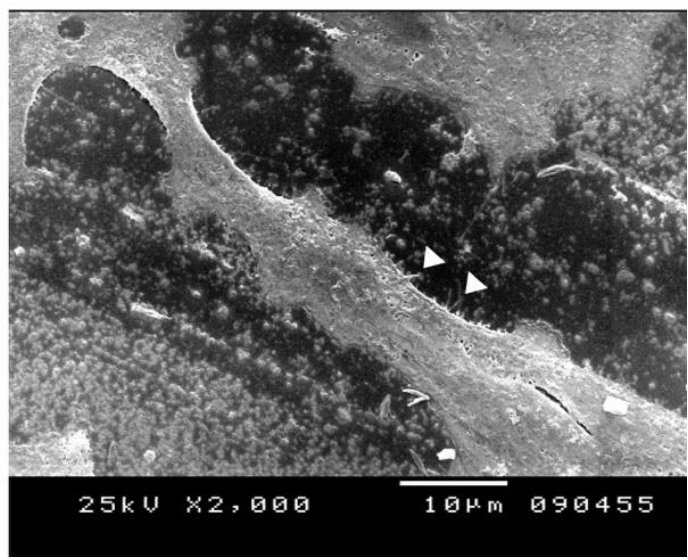

Fig. 3: SEM micrographs of a scratched A549 control monolayer culture. a. The wound was imaged 48h after scratching at low magnification to show the wound closure at different areas. b. A partially closed area of the wound with collective cell migration and cellular protrusions. c. Higher magnification of B. Arrows indicates cellular lamellipodia. d. Cell-cell contact at the wound area formed between two cells each from a different side of the wound. Arrowheads indicate cellular filopodia. 
a

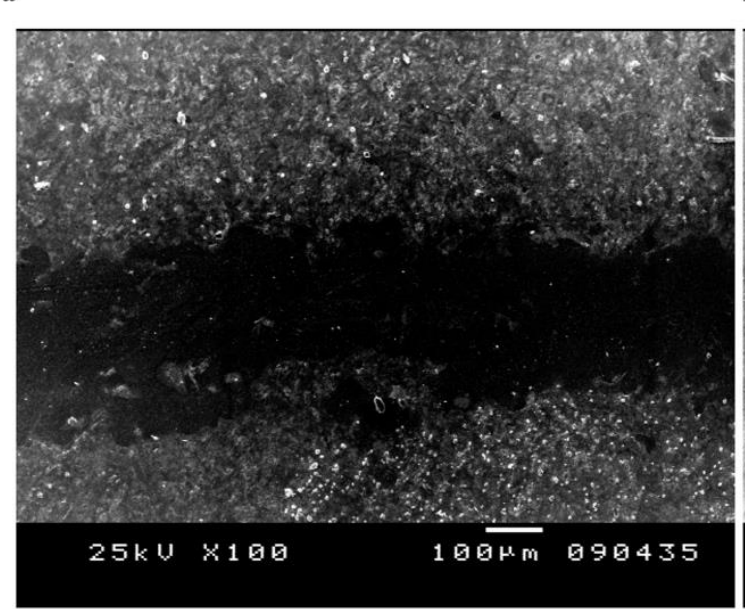

c

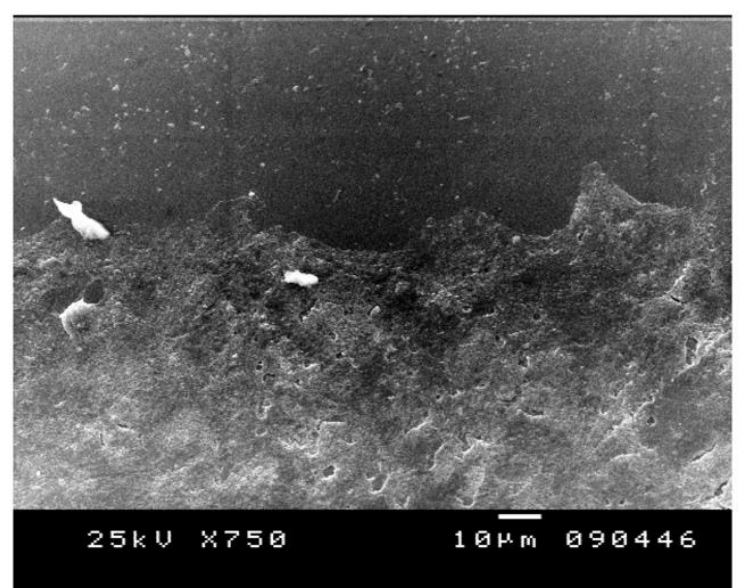

b

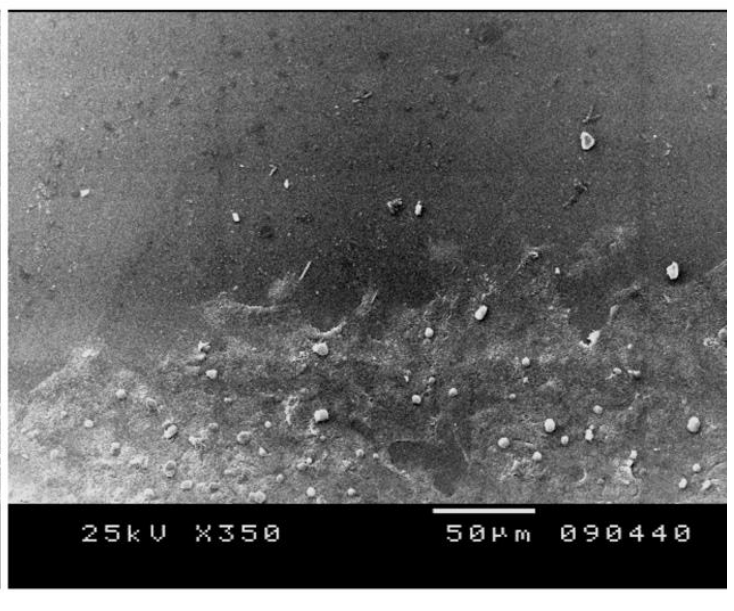

d

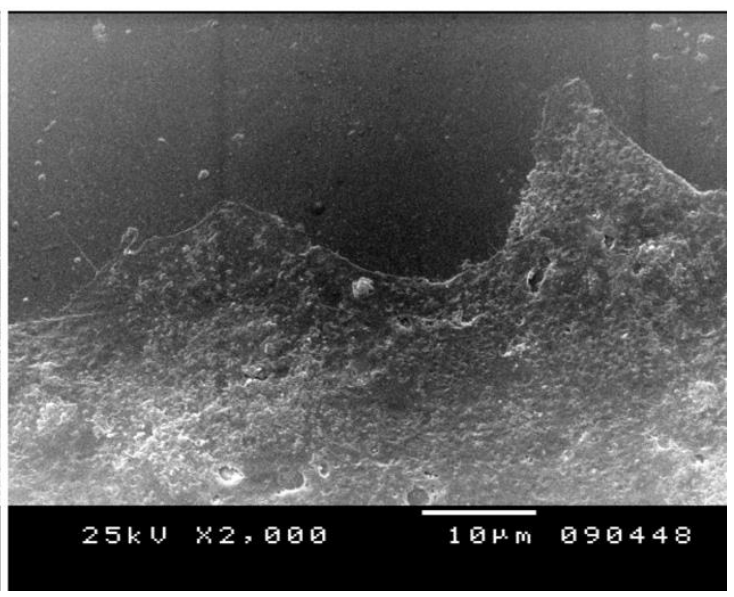

Fig. 4: SEM micrographs of a scratched A549 monolayer culture upon curcumin treatment $(20 \mu \mathrm{M})$. a. Low-power image of curcumin-treated A549 confluent monolayer at $48 \mathrm{~h}$ after scratching. Note: the wound is widely open. b. Leading cells of the wound edge appear with very limited migration potential. c. still has cellcell contact. The apical protrusions and lamellipodia of cells at the wound edge are extremely short. d. Higher magnification of figure $\mathrm{C}$ showing the absence of filipodia on the wound-facing surface of cells.

The impact of curcumin on the expression levels of adhesion and migration control proteins

We applied a quantitative real-time PCR analysis to explore the potential effect of curcumin on the expression level of Cofilin1, LIMK1, and MLCK genes. Surprisingly, we found that the expression level of LIMK1 was dramatically decreased (by more than 6-folds) as compared to control (Fig.5a). This has been accompanied by a slight decrease in the Cofilin1 gene expression by $27 \%$ as compared to control (Fig.5b). We also found a remarkable downregulation in the MLCK gene expression by 6folds as compared to controls (Fig.5c). 
a

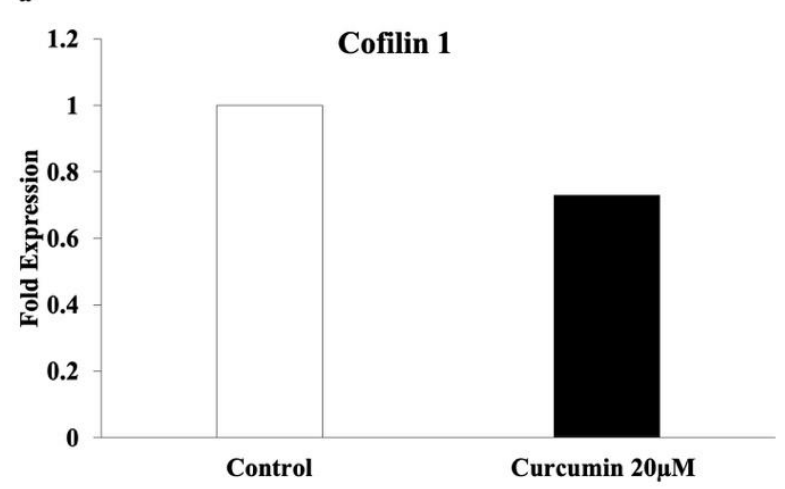

b

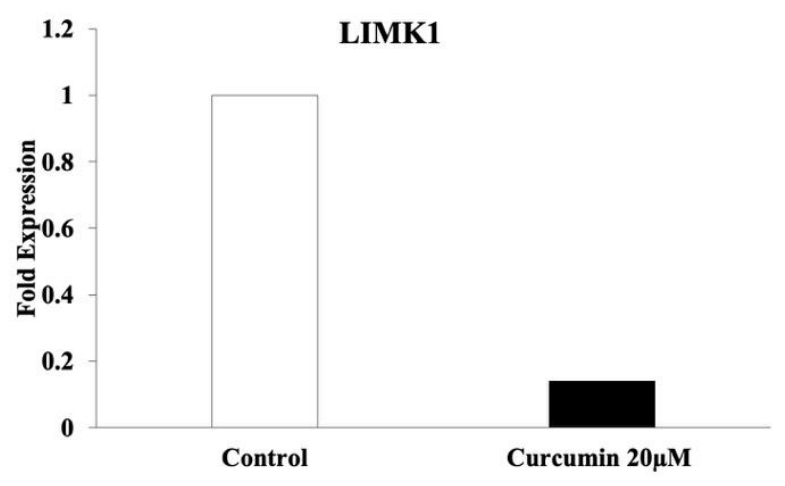

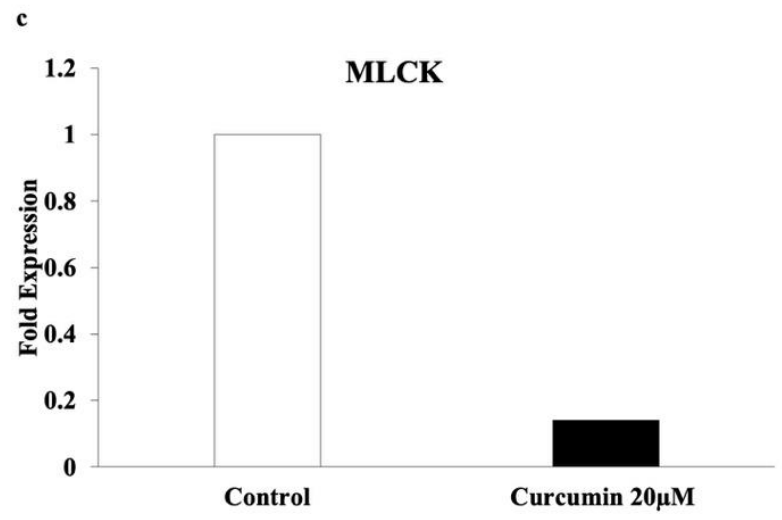

Fig. 5: Quantitative real-time PCR analysis of control and curcumin-treated cultures. Bar graphs indicate the fold change in the expression levels of Cofilin 1 (a), LIMK1 (b), and MLCK (c) about the control values.

The cytotoxic potential of the effect of curcumin on A549 cancer cells

Due to the possibility that curcumin possesses a cytotoxic effect on cells that would directly eliminate cells from our preparations. Our previously mentioned anti-migratory and anti-adhesive effect of curcumin could be also attributed to a possible cell- killing effect of the applied concentrations of curcumin. Therefore, were investigated the possible cytotoxic effect of different concentrations of curcumin $(0,5,10$, and $20 \mu \mathrm{M})$ using the MTT assay (Fig.6). Our results showed that curcumin (up to $20 \mu \mathrm{M}$ ) has no significant cytotoxic potential on A549 cancer cells. 
a

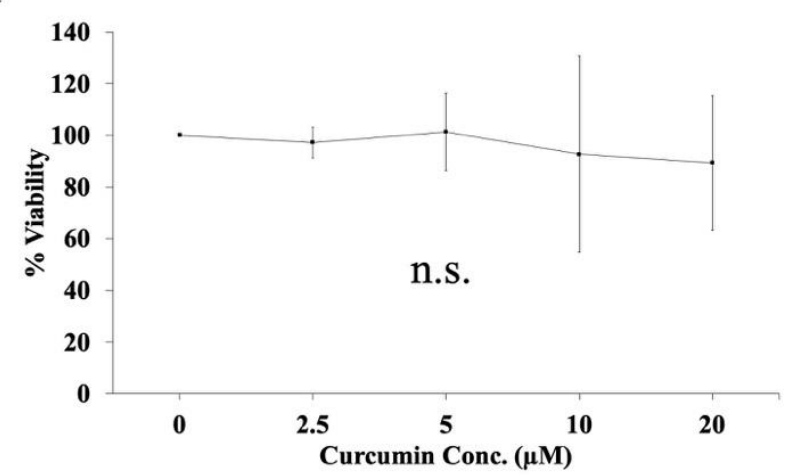

b

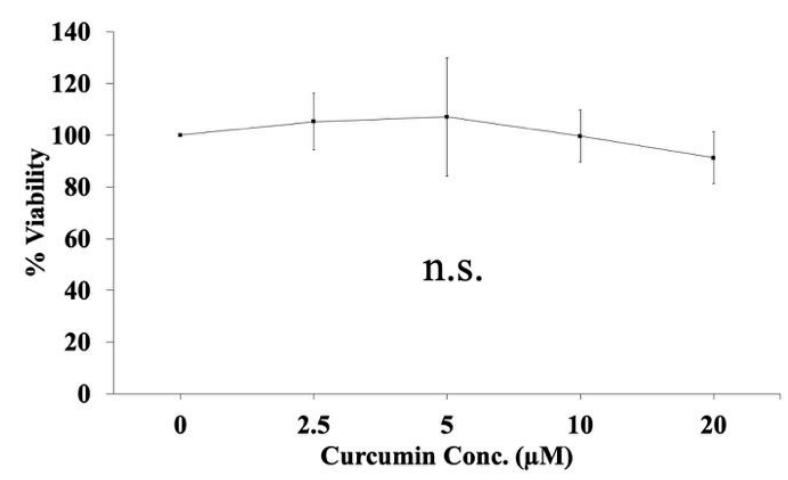

Fig. 6: Effect of curcumin on the cell viability of A549 cancer cells. Dose-response curves showing the \% viability of cells upon curcumin treatment at $24 \mathrm{~h}$ (a) and $48 \mathrm{~h}$ (b). Results are mean \pm s.d. ( $\mathrm{n}=3, t$-test, n.s. not significant).

\section{Discussion:}

Chemotherapy remains the primary therapeutic regime for advanced lung cancer, although the severe side effects of the chemotherapeutic agents usually limit the clinical outcomes of the treatment protocol (Gottschling et al. 2012). Curcumin is attracting an increasing interest due to its safety, effectiveness, and relatively low level of toxicity (Fadus et al. 2017). Recent studies have investigated the anticancer properties of curcumin and tackled its anti-metastatic aspect (Chen et al. 2008; Lin et al. 2009; Chen et al. 2014b). However, the effect of curcumin on lung cancer cell migration and adhesion as well as the exact underlying molecular mechanism remains unclear. In this work, we evaluated the potential antimigratory effect of curcumin on A549 lung cancer cells. Our results showed that curcumin attenuates the migration potential of A549 cancer cells. Our finding is consistent with the findings of (Chen et al. 2015;
Sirohi et al. 2017) who reported a possible antimigratory effect of curcumin. We also investigated the anti-adhesive effect of curcumin and found that it alters the adhesive capacity of cancer cells. Considering the crucial role of surface adhesion molecules in cell migration (Huttenlocher et al. 1995), the observed anti-adhesive action of curcumin is likely to participate in its anti-migratory potential in cancer cells.

Our scanning electron microscope study revealed that curcumin attenuated the formation of lamellipodia and filopodia in cancer cells. The formation of these protrusions is crucial for cellular motility and involves rearrangement of the cytoskeletal elements including the actin fibres (Fletcher and Mullins 2010). Therefore, the antimigratory action of curcumin could attribute to limiting the cellular ability to rearrange the microtubules of the cytoskeleton. 
Further to explore the molecular mechanism by which curcumin-induced its anti-migratory effect in cells, we analyzed the expression level of the LIMK1 gene upon curcumin treatment. This kinase directly regulates the cytoskeleton remodeling, and thus controls the process of protrusion formation. Our data showed that curcumin dramatically suppresses the expression level of both LIMK1. Also, the expression level of the cofilin1 gene (LIMK1 downstream target) was slightly downregulated. Mechanistically, LIMK1 phosphorylates and deactivates its downstream actin-depolymerizing protein cofilin1 (Ding et al. 2008). Therefore, the observed dramatic downregulation in the LIMK1 gene expression upon curcumin treatment could render cofilin1 functionally more active. The cofilin1 activity enhances depolymerization and severing of the actin filaments which may promote actin filament disassembly and disrupt the protrusion formation (Dimchev et al. 2017). We also found that curcumin downregulates the gene expression level of MLCK. The kinase activity of MLCK regulates the myosin IImediated contraction that underlies cell protrusion, traction, and retraction (Pollard and Borisy 2003). Also, MLCK activity is believed to be crucial for the generation of contraction forces that connect adhesion, protrusion, and actin organization (Gupton and Waterman-Storer 2006). Moreover, MLCK plays an essential role in the extension of lamellipodia (Chen et al. 2014a). Therefore, downregulating the expression level of MLCK might effectively cease lamellipodia extension and constrain the cellular movement. Recent work showed that the loss of MLCK disrupts the cell-cell and cell-matrix adhesions of breast epithelial cells (Kim and Helfman 2016). Therefore, our observed anti-adhesive potential of curcumin may be attributed to the ability of curcumin to downregulate the MLCK gene expression. Therefore, our findings suggest that curcumin affects the migratory potential of cancer cells via attenuating the expression level of LIMK1 and MLCK genes.

We also investigated the possible effect of curcumin on the viability of cancer cells and found that curcumin was not cytotoxic to the A549 cancer cells at concentrations up to $20 \mu \mathrm{M}$. Importantly, the inhibitory effect of curcumin on the migration of cells was statistically significant at this concentration. This eliminates the possibility that our observed antimigratory effect could be due to a direct killing effect of the applied concentration of curcumin. In coincidence with our findings, a recent study reported that the cytotoxic effect of curcumin in 801D lung cancer cells was not statistically significant at low doses (Chen et al. 2014b). Moreover, the results of this study suggested that cell death or apoptosis is not the main factor for limiting the migration ability of lung cancer cells.

\section{Summary and conclusion}

Taken together, curcumin can attenuate migration and adhesion potentials of A549 cancer cells at nontoxic concentrations. Mechanistically, its activity could be attributed to downregulating the LIMK1 and MLCK proteins. Therefore, curcumin should be considered as an effective anti-migratory pharmacological agent in lung cancer. Further investigations are necessary to understand the complete mechanism of action of curcumin on the cellular motility pathways.

\section{Conflict of interests}

The authors declare that they have no competing interests.

\section{References:}

Bacevic K, Noble R, Soffar A, Wael Ammar O, Boszonyik B, Prieto S, Vincent C, Hochberg ME, Krasinska L, Fisher D (2017) Spatial competition constrains resistance to targeted cancer therapy. Nat Commun 8:1995. DOI: 10.1038/s41467-017-01516-1

Bray F, Ferlay J, Soerjomataram I, Siegel RL, Torre LA, Jemal A (2018) Global cancer statistics 2018: GLOBOCAN estimates of incidence and mortality worldwide for 36 cancers in 185 countries. CA Cancer J Clin. DOI: 10.3322/caac. 21492 
Chen C, Tao T, Wen C, He W-Q, Qiao Y-N, Gao YQ, Chen X, Wang P, Chen C-P, Zhao W, Chen H-Q, Ye A-P, Peng Y-J, Zhu M-S (2014a) Myosin light chain kinase (MLCK) regulates cell migration in a myosin regulatory light chain phosphorylationindependent mechanism. J Biol Chem 289:28478-28488.

DOI:

\subsection{4/jbc.M114.567446}

Chen H-W, Lee J-Y, Huang J-Y, Wang C-C, Chen W-J, Su S-F, Huang C-W, Ho C-C, Chen JJW, Tsai M-F, Yu S-L, Yang P-C (2008) Curcumin inhibits lung cancer cell invasion and metastasis through the tumor suppressor HLJ1. Cancer Res 68:7428-7438. DOI: 10.1158/0008-5472.CAN-07-6734

Chen Q, Gao Q, Chen K, Wang Y, Chen L, Li X (2015) Curcumin suppresses migration and invasion of human endometrial carcinoma cells. Oncol Lett 10:1297-1302. DOI: 10.3892/ol.2015.3478

Chen Q, Zheng Y, Jiao D, Chen F, Hu H, Wu Y, Song J, Yan J, Wu L, Lv G (2014b) Curcumin inhibits lung cancer cell migration and invasion through Rac1-dependent signaling pathway. J Nutr Biochem 25:177-185. DOI: 10.1016/j.jnutbio.2013.10.004

Deng YI, Verron E, Rohanizadeh R (2016) Molecular Mechanisms of Anti-metastatic Activity of Curcumin. Anticancer Res 36:5639-5647. DOI: $10.21873 /$ anticancer.11147

Dimchev G, Steffen A, Kage F, Dimchev V, Pernier J, Carlier M-F, Rottner K (2017) Efficiency of lamellipodia protrusion is determined by the extent of cytosolic actin assembly. Mol Biol Cell 28:1311-1325. DOI: 10.1091/mbc.e16-05-0334

Ding Y, Milosavljevic T, Alahari SK (2008) Nischarin Inhibits LIM Kinase To Regulate
Cofilin Phosphorylation and Cell Invasion.

Mol Cell Biol 28:3742-3756. DOI: 10.1128/MCB.01832-07

Fadus MC, Lau C, Bikhchandani J, Lynch HT (2017)

Curcumin: An age-old anti-inflammatory and anti-neoplastic agent. J Tradit Complement Med 7:339-346. DOI: 10.1016/j.jtcme.2016.08.002

Fletcher DA, Mullins RD (2010) Cell mechanics and the cytoskeleton. Nature 463:485-492. DOI: 10.1038/nature08908

Goldstraw P, Chansky K, Crowley J, Rami-Porta R, Asamura H, Eberhardt WEE, Nicholson AG, Groome P, Mitchell A, Bolejack V, International Association for the Study of Lung Cancer Staging and Prognostic Factors Committee, Advisory Boards, and Participating Institutions, International Association for the Study of Lung Cancer Staging and Prognostic Factors Committee Advisory Boards and Participating Institutions (2016) The IASLC Lung Cancer Staging Project: Proposals for Revision of the TNM Stage Groupings in the Forthcoming (Eighth) Edition of the TNM Classification for Lung Cancer. J Thorac Oncol Off Publ Int Assoc Study Lung Cancer 11:39-51. DOI: 10.1016/j.jtho.2015.09.009

Gottschling S, Schnabel PA, Herth FJF, Herpel E (2012) Are we missing the target? Cancer stem cells and drug resistance in non-small cell lung cancer. Cancer Genomics Proteomics 9:275-286

Guo W, Wang N, Feng Y (2017) Recent Progress on the Molecular Mechanisms of Anti-invasive and Metastatic Chinese Medicines for Cancer Therapy. In: Latosinska JN, Latosinska M (eds) Unique Aspects of Anticancer Drug Development. InTech 
Gupton SL, Waterman-Storer CM (2006) Spatiotemporal Feedback between Actomyosin and Focal-Adhesion Systems Optimizes Rapid Cell Migration. Cell 125:1361-1374.

DOI: 10.1016/j.cell.2006.05.029

Huttenlocher A, Sandborg RR, Horwitz AF (1995) Adhesion in cell migration. Curr Opin Cell Biol 7:697-706

Kim DY, Helfman DM (2016) Loss of MLCK leads to disruption of cell-cell adhesion and invasive behavior of breast epithelial cells via increased expression of EGFR and ERK/JNK signaling. Oncogene 35:44954508. DOI: $10.1038 /$ onc. 2015.508

Lakshmanan I, Rachagani S, Hauke R, Krishn SR, Paknikar S, Seshacharyulu P, Karmakar S, Nimmakayala RK, Kaushik G, Johansson SL, Carey GB, Ponnusamy MP, Kaur S, Batra SK, Ganti AK (2016) MUC5AC interactions with integrin $\beta 4$ enhances the migration of lung cancer cells through FAK signaling. Oncogene 35:4112-4121. DOI: 10.1038/onc. 2015.478

Li X, You M, Liu Y, Ma L, Jin P, Zhou R, Zhang ZX, Hua B, Ji X, Cheng X, Yin F, Chen Y, Yin W (2017) Reversal of the Apoptotic Resistance of Non-Small-Cell Lung Carcinoma towards TRAIL by Natural Product Toosendanin. Sci Rep 7: DOI: 10.1038/srep42748
Lin S-S, Lai K-C, Hsu S-C, Yang J-S, Kuo C-L, Lin J-P, Ma Y-S, Wu C-C, Chung J-G (2009) Curcumin inhibits the migration and invasion of human A549 lung cancer cells through the inhibition of matrix metalloproteinase- 2 and -9 and Vascular Endothelial Growth Factor (VEGF). Cancer Lett 285:127-133. DOI: 10.1016/j.canlet.2009.04.037

Pollard TD (2016) Actin and Actin-Binding Proteins. Cold Spring Harb Perspect Biol 8:a018226 . doi: 10.1101/cshperspect.a018226

Pollard TD, Borisy GG (2003) Cellular motility driven by assembly and disassembly of actin filaments. Cell 112:453-465

Popper HH (2016) Progression and metastasis of lung cancer. Cancer Metastasis Rev 35:75-91 . doi: 10.1007/s10555-016-9618-0

Sirohi VK, Popli P, Sankhwar P, Kaushal JB, Gupta K, Manohar M, Dwivedi A (2017) Curcumin exhibits anti-tumor effect and attenuates cellular migration via Slit-2 mediated downregulation of SDF-1 and CXCR4 in endometrial adenocarcinoma cells. J Nutr Biochem 44:60-70. DOI: 10.1016/j.jnutbio.2016.12.021

Ye M-X, Li Y, Yin H, Zhang J (2012) Curcumin: updated molecular mechanisms and intervention targets in human lung cancer. Int J Mol Sci 13:3959-3978. DOI: 10.3390/ijms 13033959 